The International Journal Of Engineering And Science (IJES)

|| Volume || 6 || Issue || 1 || Pages || PP 24- 32|| 2017 ||

ISSN (e): $2319-1813 \operatorname{ISSN}$ (p): $2319-1805$

THE IJES

\title{
Tectonic Method for Traditional Longhouse the Core Form of So Langkepatamuan Architecture
}

\author{
Paul Alexander Wuysang ${ }^{1}$, Josef Prijotomo ${ }^{2}$, Yohanes Basuki Dwisusanto ${ }^{3}$ \\ ${ }^{1}$ Parahyangan Catholic University, Indonesia \\ ${ }^{2}$ Sepuluh November Institute of Technology, Indonesia \\ ${ }^{3}$ Parahyangan Catholic University, Indonesia
}

\begin{abstract}
-
So many architectural research efforts that have been conducted so far merely describing the traditional longhouse as an artefact. Thick descriptions performed to find the fact behind the visual evidence of the architecture of longhouses. However, those describing methods only give the audience narrow understandings of the traditional so langkepatamuan longhouse architecture. Tectonic method aim is to reveal the tectonic meanings behind the surface of the visual evidence. In this research report, tectonic views oriented to the mechanic form of the longhouse. Traditional so langkepatamuan longhouse as mechanic form are critical values of the ancient Dayak Taman craftsmanship. Tectonic method could show the aspects of mechanical structures of the Dayak Taman house. Those aspects of mechanical structures of core form consist of the method of constructions, logic of structure, and the art of joint. The method of construction so langkepatamuan is iron wood frame system with salaman system joints that work against local foundation settlement. In another hand, the art of joint shows there are three interconnected pairs of joint that works together as two dimensions wooden frame.Those tree aspects could redefine the previous meanings of so langkepatamuan architecture as visual evidence. By exploring the core form of so langkepatamuan longhouse, scientist could perceive the evidence of the art of thinking and making of Dayak Taman architecture. Finally, tectonic method could have capability to broaden the perception about longhouse architecture.
\end{abstract}

Keyword: longhouse, tectonic method, method of construction, logic of structure, art of joints

Date of Submission: 09 January 2017

$\longrightarrow$ r

Date of Accepted: 26 January 2017

\section{INTRODUCTION}

This paper connect with layers of construction efforts as s complex process to reveal a wooden frame logic behind the traditional longhouse buildings. It should be noted that layers of crafting will be trace to the predetermined and the final structure as some continuity process of making and revealing. It is a tough questions, because Dayak ancestor brings the structure a form from the single tool of beliung (Dayak axe likes tool).

Tectonic analysis connects with the layers of thinking and making of traditional longhouse. Yet, so many experts gave so little attention to those objects. Many research design dedicates to much effort to describe the traditional longhouse as merely an artefact. The most basic effort of longhouse research had been conducted by architectural researchers such as Winzeler were full thick of documentation with so little explanations about the effort behind the Dayak huge structure. Some report are too archeological for an architect to read as design resource. So, this archeological report had created a loop niche for misunderstanding about past Dayak craftsmanship.

So LangkePatamuan(longhouse for tribal meeting) has shown the evidence that beliung (indigenous axe likes tools) gave the capability of Taman people the ability and the capability to creating the huge structure from the scratch. It meant doing the agile activity from cutting the iron tree of belian, shape it, and assemble it to as a process of group of Taman people to build the wooden frame structure. To see the enemy, the building structure should be taller than the capability of the enemy to climb the structure. When the ngayau (headhunting) culture was still practiced, high level $t a$ 'so(corridor) became priority for Taman builder because high floor level would be safer to avoid the enemy infiltration. Therefore the longhouse structure is the safest place on earth (Kalimantan Island) in ancient time.

Today, longhouses are still spread across Kalimantan Island, but the longhouses numbers are kept decrease during the years. This ancient forms have been faded away by the modern architecture, so some ancient features of crafted method of Dayak could be missing. Therefore, tectonic method could be traces back by using tectonic method. Tectonic method oversaw the logical way of joint system should behave regarding of working load 
during the years. The behavior of salaman join when it performed, it could gain the logic of structure of so langkepatamuan. Then the oldest coreform of so langkepatamuan could reveal its tectonic understanding.

\section{LOCATION OF SO LANGKE PATAMUAN}

So LangkePatamuan is located in Melapi I village of $0^{\circ} 47^{\prime} 00^{\prime \prime}$ N $112^{\circ} 57^{\prime} 0^{\prime \prime}$. It was built in 1941 by Dayak Taman of Kapuas Hulu Regency. It was made of rounded belian post and frame. Renovation had been conducted in 2009 with minor changes. The genuine post and timber beams structures are still applied. The biggest size of the timber post has diameter of $35 \mathrm{~cm}$ with the length of 15 meter. The floor level has 4.5 meter from the ground. It provided higher ground to avoid intruder during ngayau culture is still practiced by Dayak in Kalimantan Island.

\section{TECTONIC METHOD OF THE ANALYSIS OF LONGHOUSE COREFORM}

The tectonic method has some layers of understanding as elaboration method of Botticher, Salvadori, and the author. Those layers were sediments of Dayak Taman knowledge that had been useful to build the so langkepatamuan longhouse. Previous wooden frame knowledge sure will be so critical from this method. By simulating the process of thinking and making of Dayak Taman developing effort, it will find some categories' that working in triadic model of thinking. Sure, the first category is material. Without material no longhouse can be built.

Second, the second category is gravity. The awareness of gravity will make the Dayak builder learn how to estimate the process of cutting, transporting, erecting, and assembling the longhouse structure. The gravity was dictated the longhouse wooden materials.

Third, the third category is method. The method is the consciousness force that is driven the Dayak craftsman to think; from taking the wood material from the forest on the banks of the main river until punching and crafting the wooden structure to be a complete form of longhouse. A method was created by Dayak craftsman as a way to shape the longhouse structure within the thought of two categories of material and gravity.

Those triadic thought (material-gravity-method) will work simultaneously for a Dayak craftsman. It will be understood that triadic thought of tectonic method has some relations that could be connected the three categories as a one single spark of structural thinking. The structural thinking is called the core formof tectonic thinking.

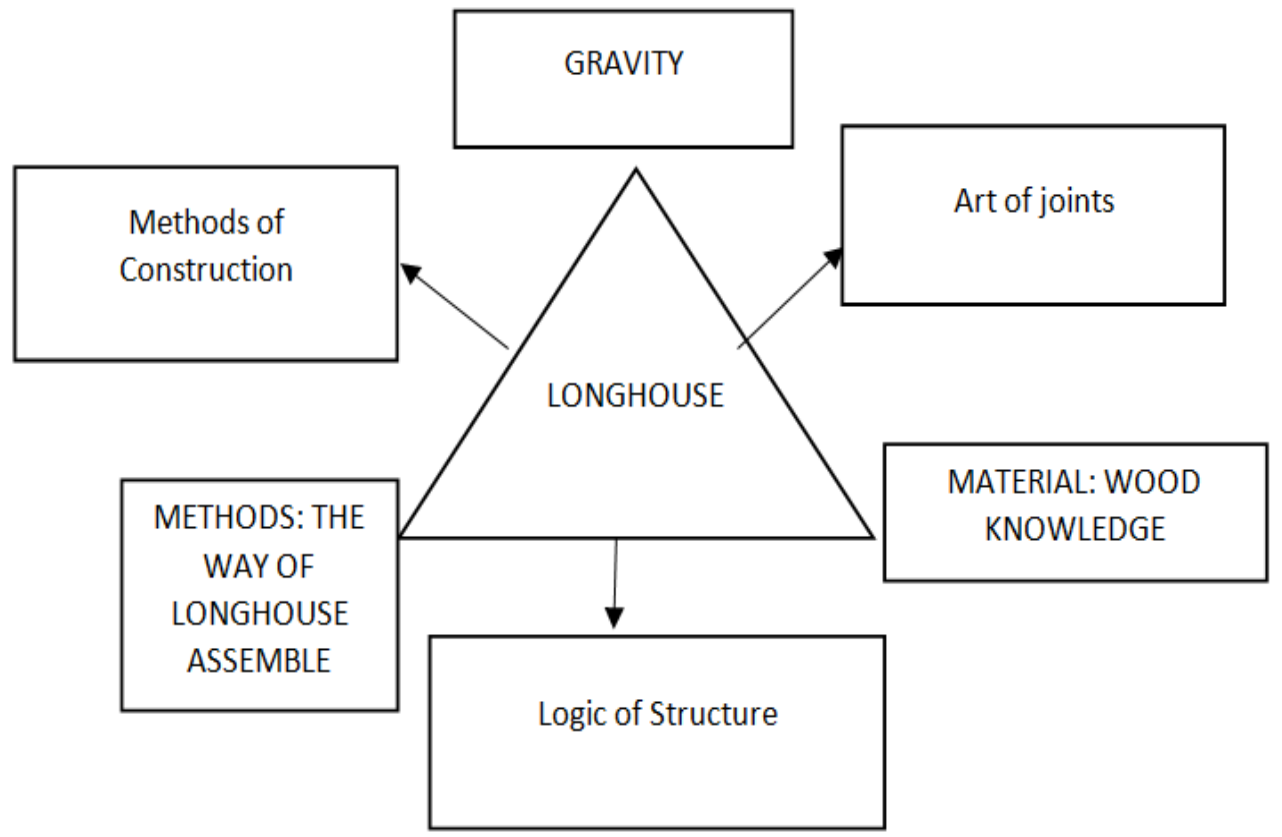

Figure 1. Tectonic Thought

Those are certain relation between three categories. The method of construction for example is a relation between method and gravity. The gravity dictate the weight of the longhouse material therefore it needs some methods to construct the longhouse construction. Both gravity and the method thought create a method of construction to build the longhouse structure. Then the art of joint is created by the thought of wooden material and gravity. The joint prevent the structural elements damaged. Furthermore the logic of structure is created by the thought of material and method. Certain material creates some logically method to assemble it. 


\section{IMPLEMENTATION}

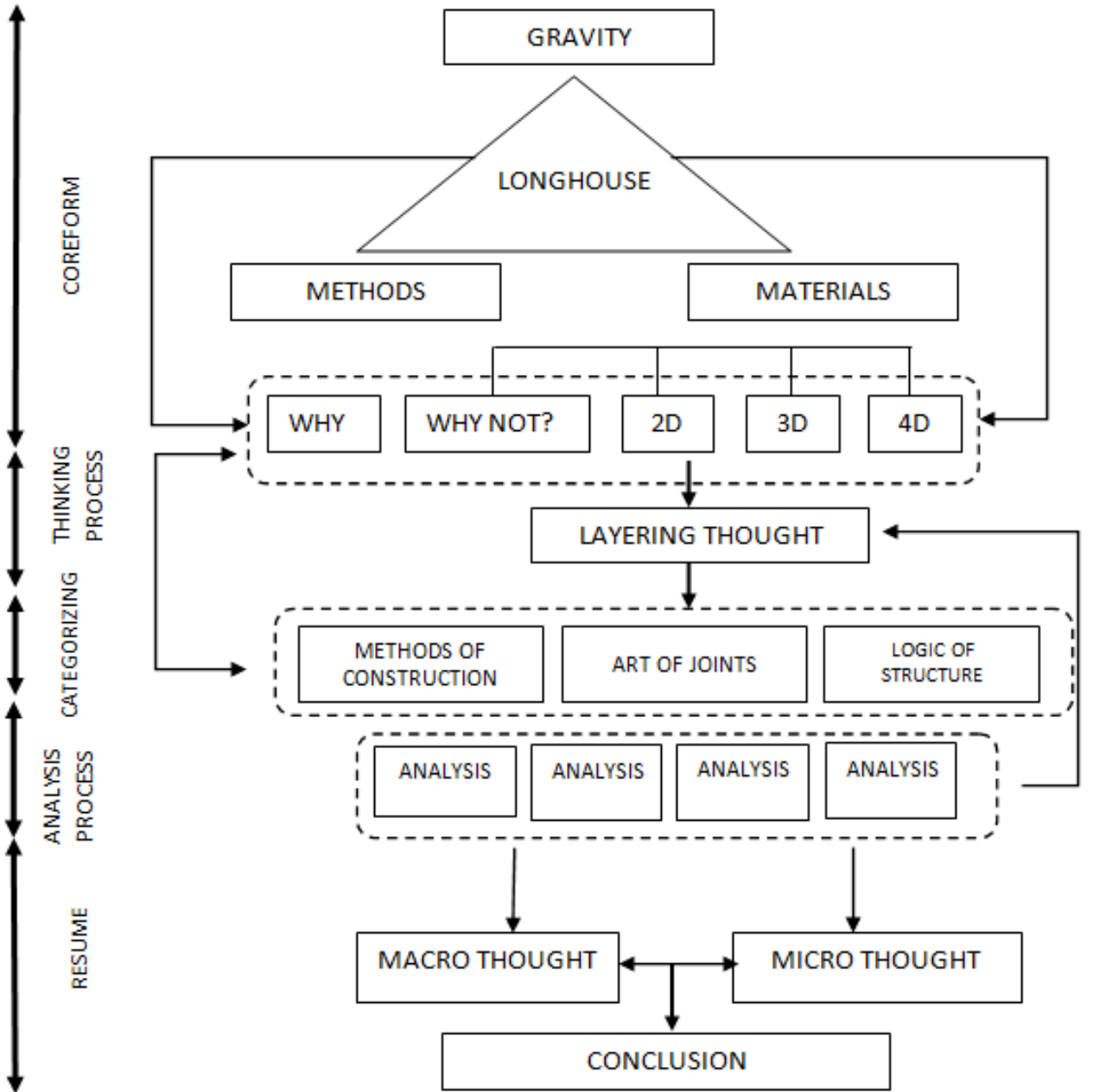

The use of tectonic method has been studied in previous architectural research of longhouses in West Kalimantan Province by Winzeler. This research was performed to develop the solution during the reconstruction process of the longhouses in West Kalimantan. The reconstruction of thinking process include the way of thinking that laid in the structure of the longhouse. Verification by interviewing the Dayak local builder had been conducting to acquire complete sight of the tectonic method.The tectonic method scheme above that is shown can explain how to collect the data during field research to the longhouse. Predetermined knowledge should acquire before the trip to the traditional longhouse location. Layers of the tectonics knowledge should be revealed by five question those are 'why', ' why not/', '2D', '3D', '4D' eyes then comparing the experience between the villagers who lived in the longhouse. It will give so many facts. The facts should be analysis to its tectonic understandings. By doing so, it will be two categories of the elements of the longhouse that have macro thought from elements as a whole and micro thought from elements of structure as a single joint. How a whole macro structure works and a micro joint works. Finally, it will conclude the tectonic method to the final conclusion. The 'why facts' will show the entire structure of the longhouse while the why not facts will think in the opposite direction or in binary opposition fashion. For instance, in the structure of wooden roof frame that apply diagonal beam in general practice will be eliminated to see the result for the structure; still possess structural stability. The question 'why' will describe the longhouse structure. The 'why not' question will ask the answer from the "why" question in binary opposition mode so, it will generate other answer. The D is thinking in one dimension of single joint. The 2D is thinking in two dimension of structure. Meanwhile, the 3D is thinking in three dimension of structure. Finally, the 4D is thinking in space and time of construction and how the structure could stand up for years without collapsed, what will happened with the stability of structure for some period of time. Then, It will triangulate the information about longhouse structure experience among the carpenters who lived in the longhouse. It will give so many facts. The facts should be analysis to its tectonic understandings. By doing so, it will be categorized the core form in three categories those are methods of construction, logic of structure, and art of jonts. . Finally, it will conclude the tectonic method as the final conclusion. 


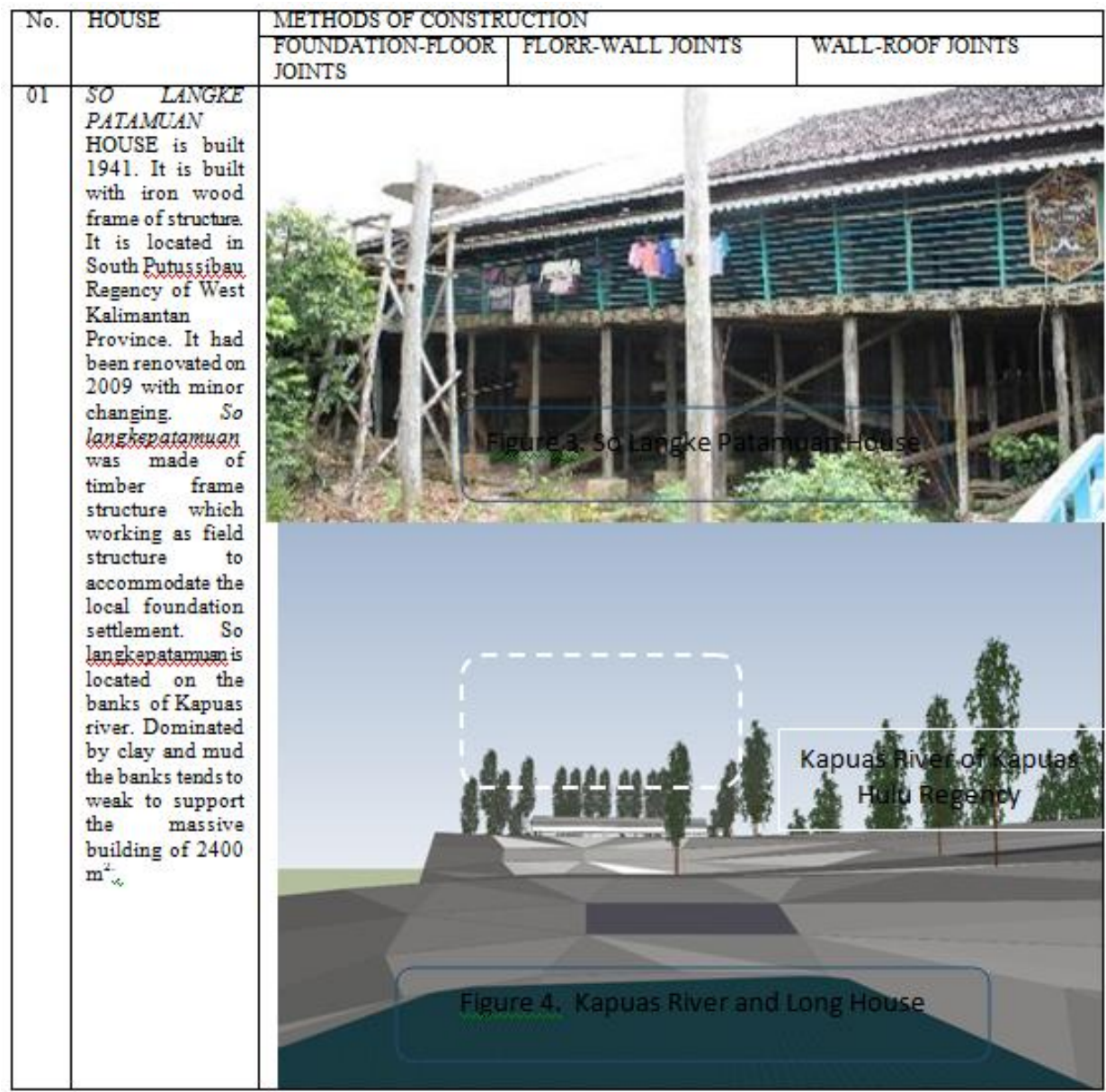

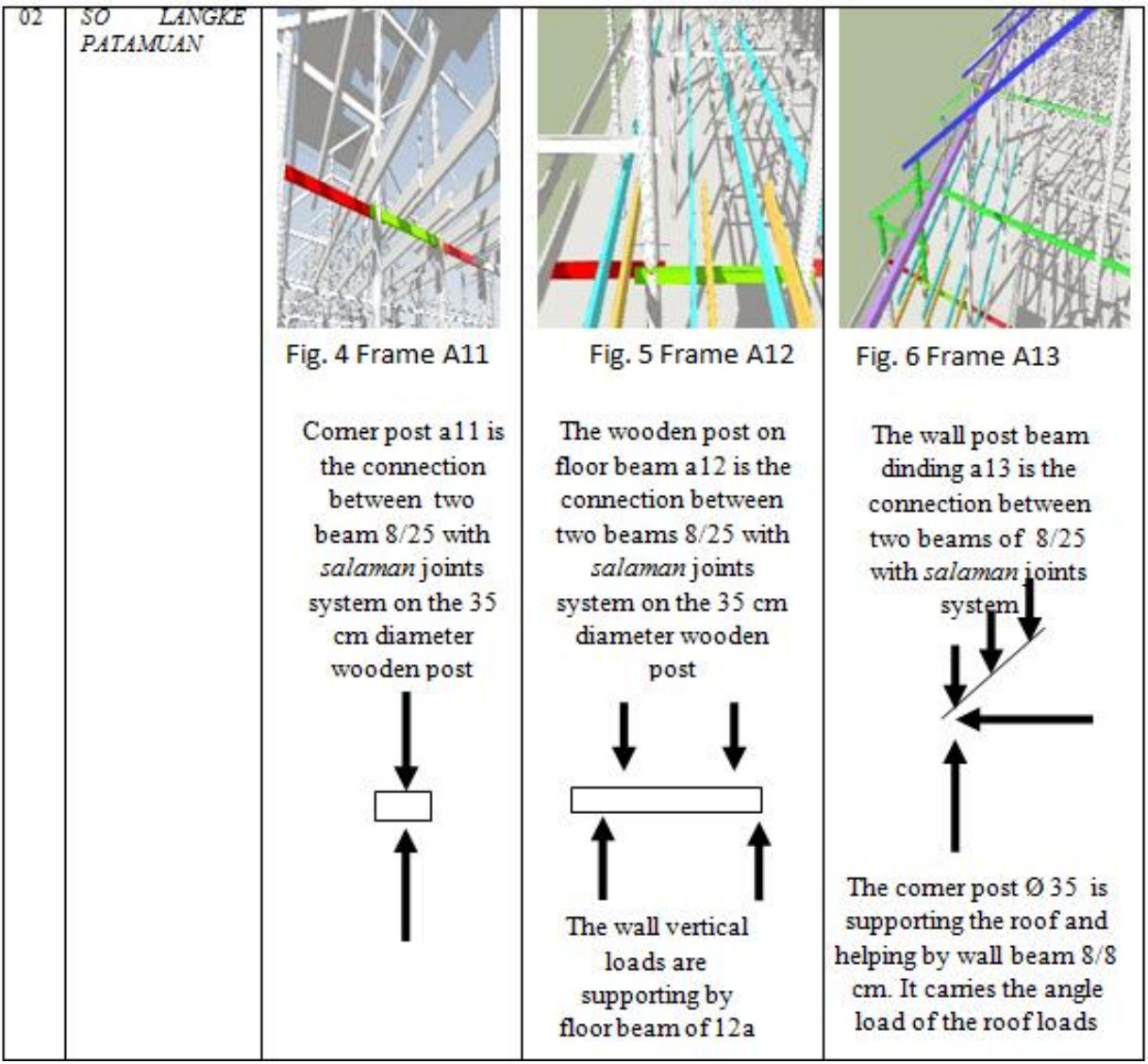




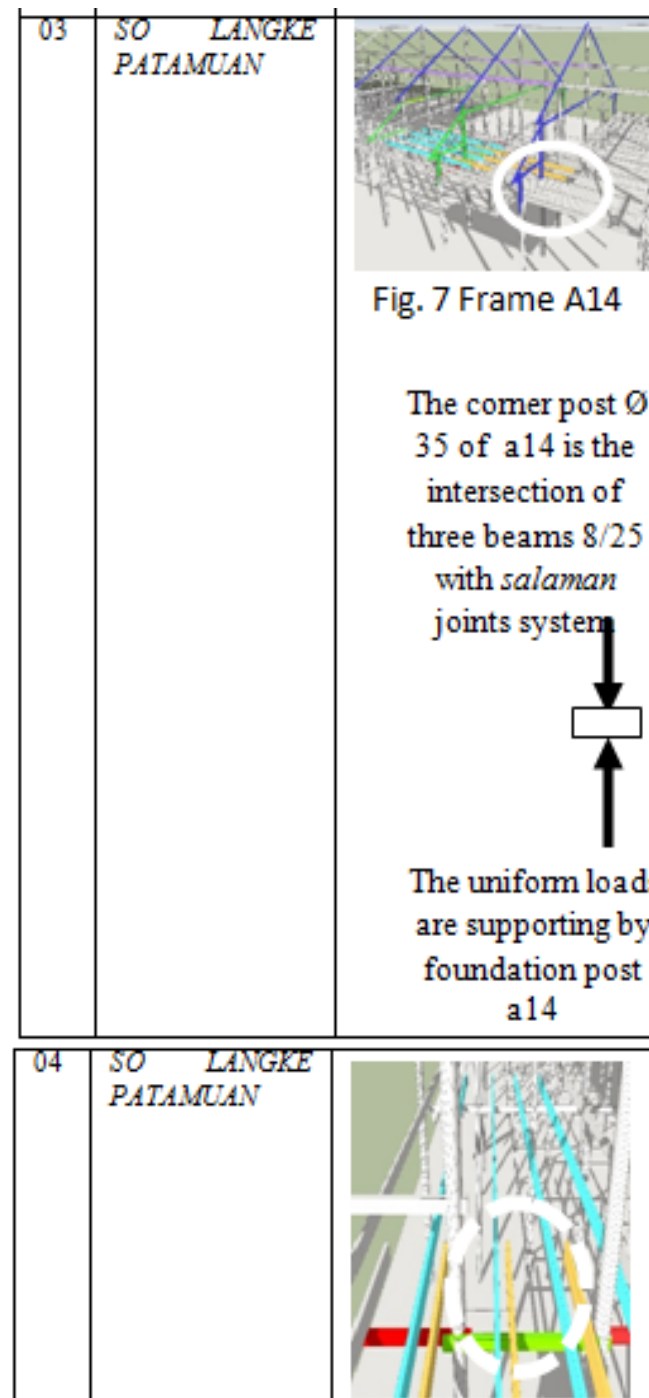

Fig. 10 Frame A17

The comer post $35 \mathrm{~cm}$ diameter of a15 is the intersection of two beams $8 / 25$ $\mathrm{cm}$ with salaman joints system

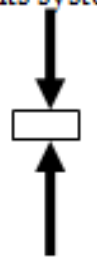

The uniform loads of the floor are supporting by foundation post 35 $\mathrm{cm}$ diameter

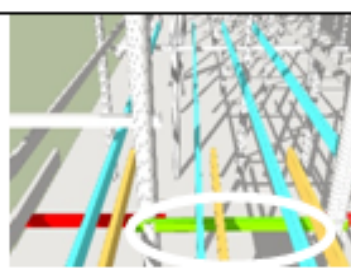

Fig. 8 Frame A15

The middle post of floor beam of a 15 is intersection of three beams with salaman joints

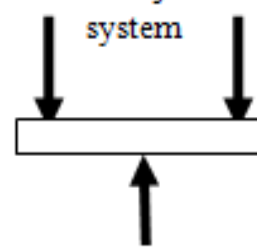

The vertical loads of the wall beam $8 / 8 \mathrm{~cm}$ are supported by floor beam $8 / 8 \mathrm{~cm}$

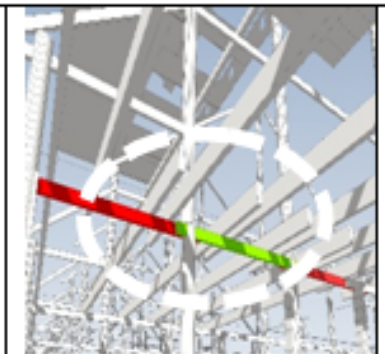

Fig. 11 Frame A18

The comer beam $8 / 8$ of $a 16$ is intersection of two beams $8 / 25$ with salaman joints system

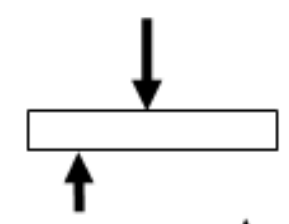

The vertical load f wall post $8 / 8 \mathrm{~cm}$ are supporting by floor beam $8 / 8 \mathrm{~cm}$.

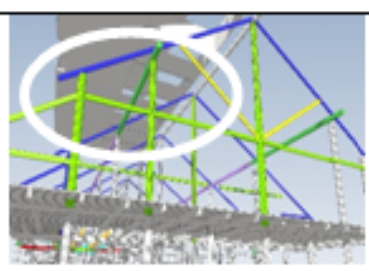

Fig. 9 Frame A16

The post wall of wall beam of a 16 is the intersection of three beams $8 / 25 \mathrm{~cm}$ with salaman joints sylstem

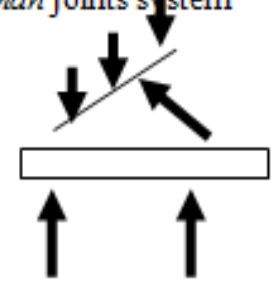

The comer post are supporting the loads of the roof and the wall beam $8 / 8 \mathrm{~cm}$

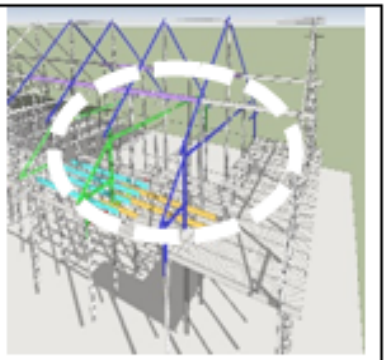

Fig. 12 Frame A19

The supporting wall beam a 17 is the intersection of two beams of $8 / 25$ with salaman joint system.

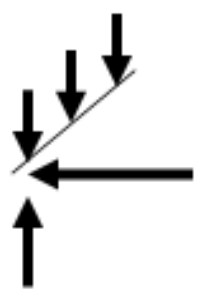

The comer post is supporting the roof loads with wall beam $8 / 8 \mathrm{~cm}$. 


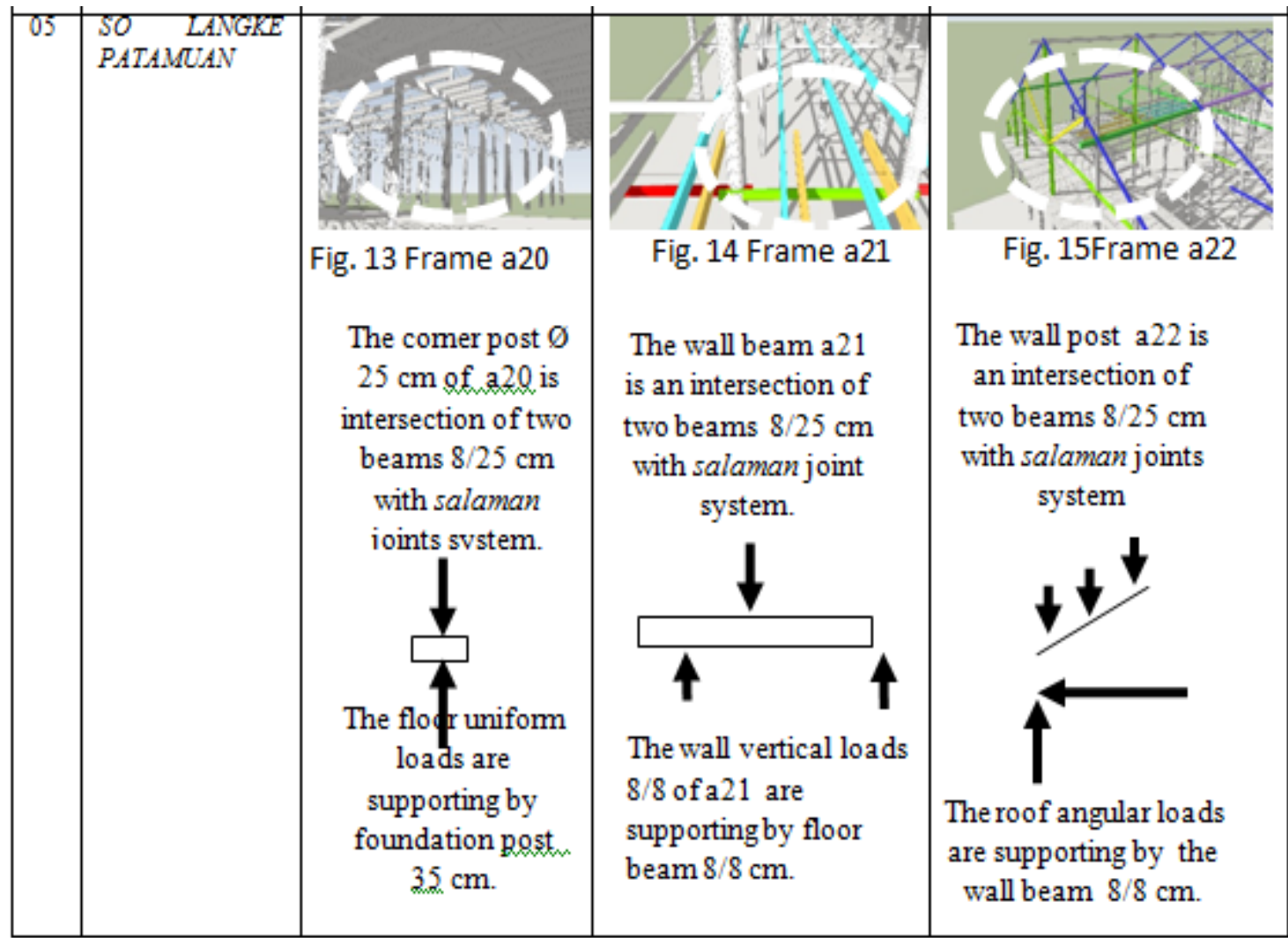

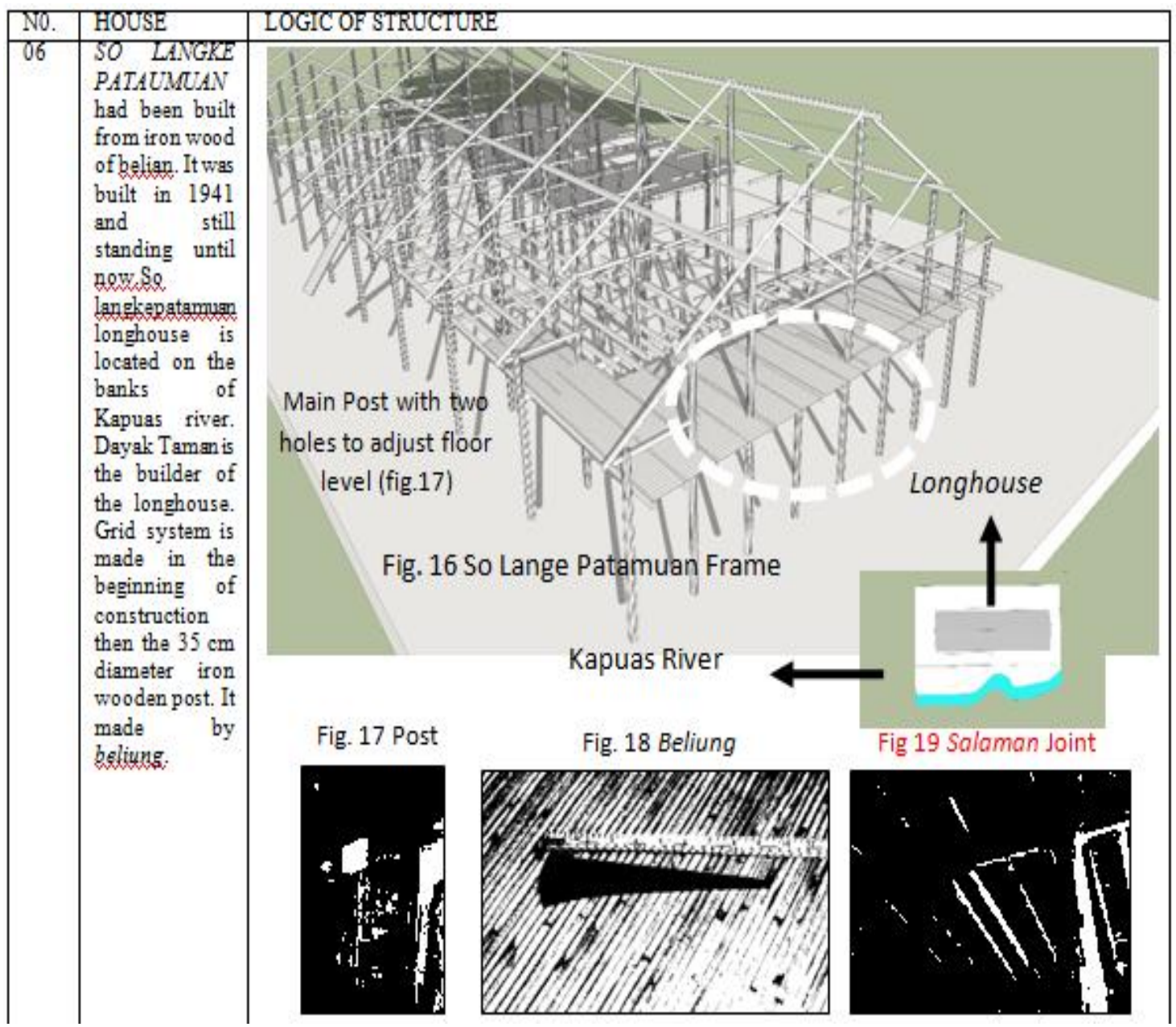




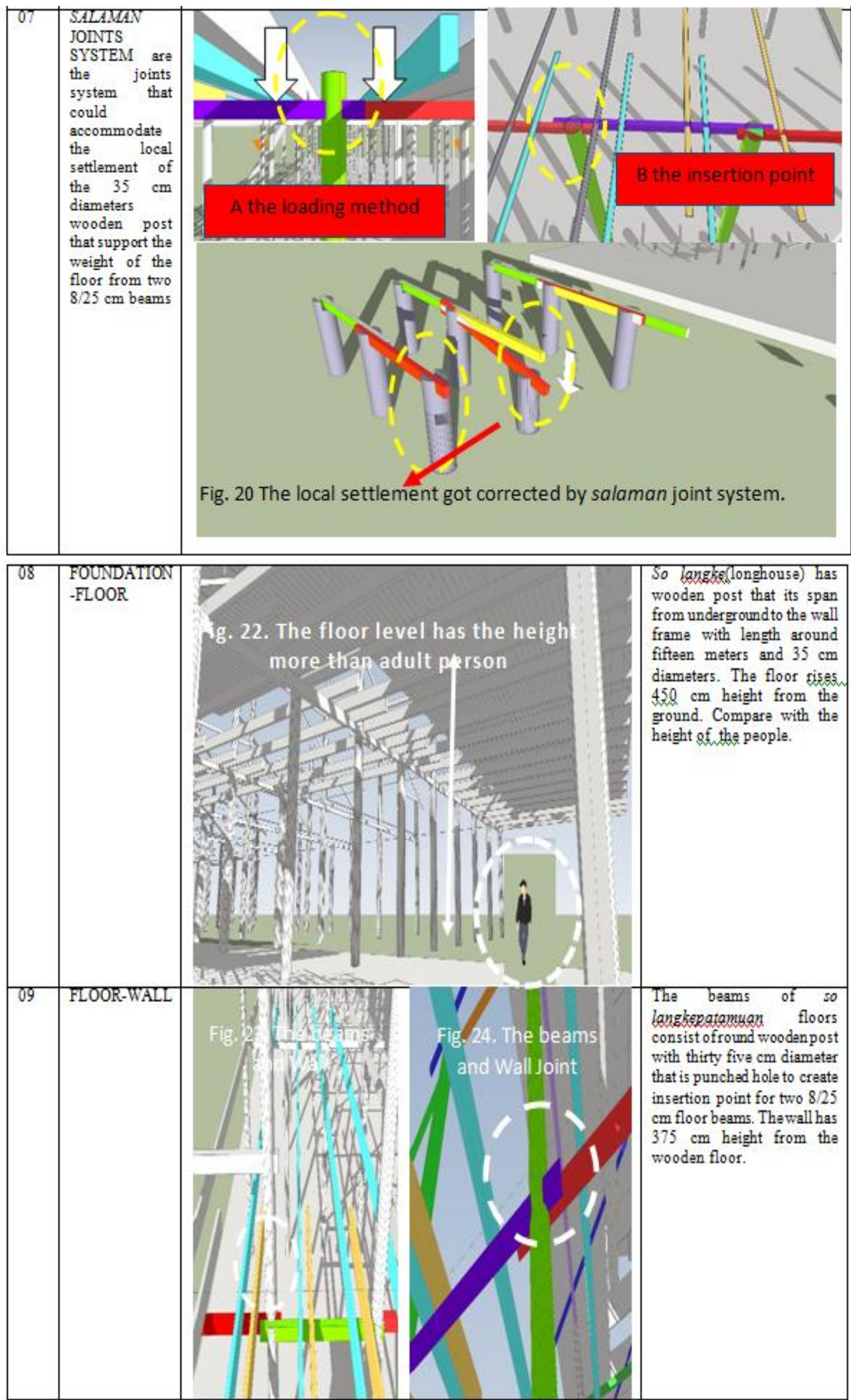




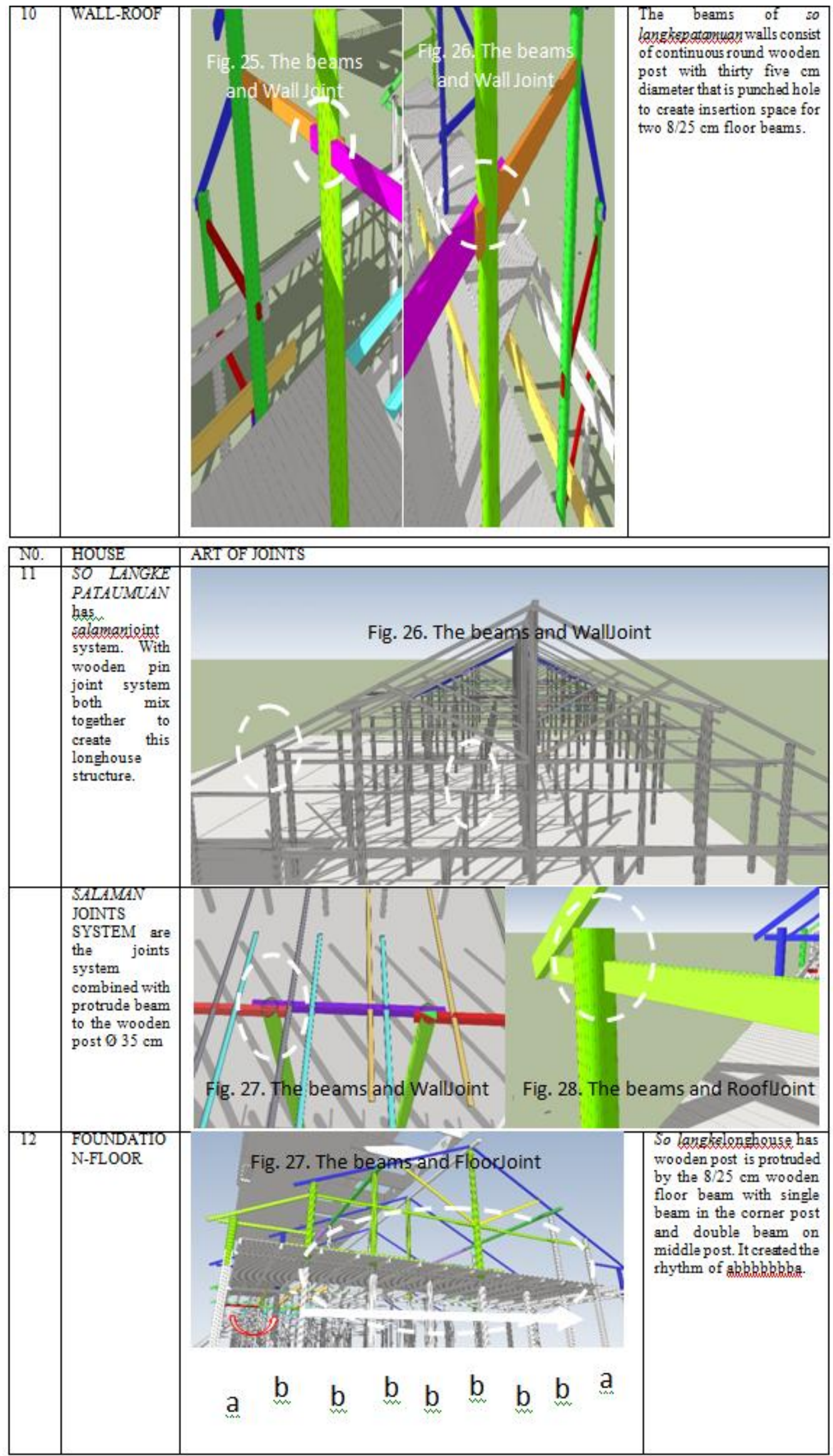




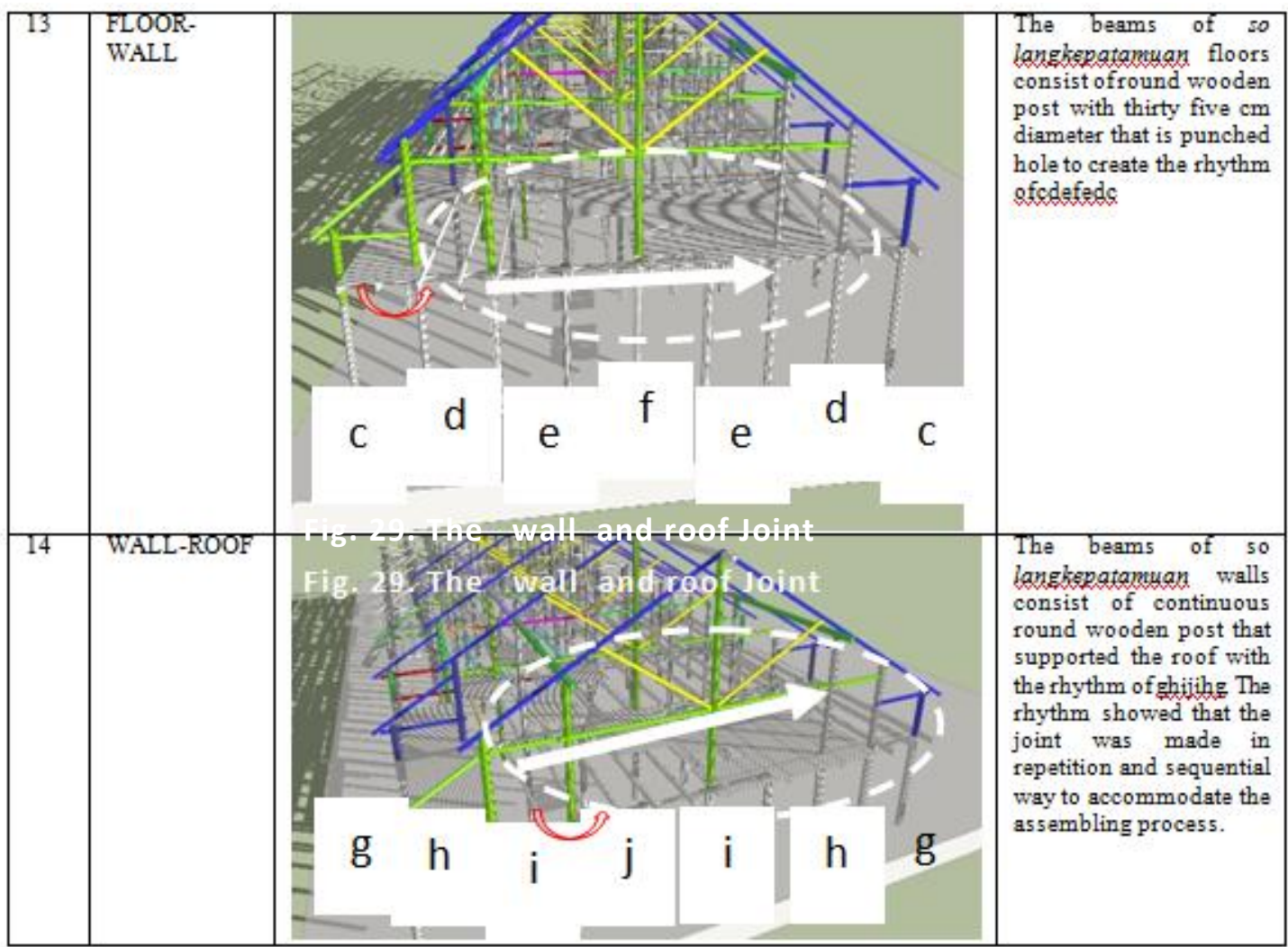

\section{CONCLUSION}

Tectonic method that consists of three categories of thinking; materials, methods, gravity. In this research, the tectonic method can be resumed that so langkepatamuan method of construction consists of wooden frame system with salaman joints system. As logic of structure, Salaman joints system had been invented by Dayak Taman builder to accommodate the local settlement of its wooden post (its local settlement could be presumed as a consequence of the longhouse location on the banks of the Kapuas river that consists of clay sediment). As an indigenous innovation, salaman joint system has been adequate to keep the longhouse form stand up so far, because the local settlement of the main wooden post could be adjusted by protruding the upper level of the post. By performing that task, it could be stabilizedthe floor structure. Therefore, it is understood that the relation of coreform- joints is the key to understand the indigenous joint system. As a researchmethod should be applied by traditional longhouse researchers. Doing so, it will enhance the capability of researchers to perceive the critical aspects in structural form of longhouse architecture. Finally, will be beneficial for an architect if he could possess tectonic insight as a creative thinker in art of thinking and making of longhouse.

\section{GLOSSARIUM}

[1]. $\quad$ Ngayau: headhunting is the way of Dayak to practice heroism and honor among them. It was already stopped in 1898 of TumbangAnoiagreement when Dayak Chiefs accorded to decline that cultural practice. TumbangAnoi is located in the Middle Kalimantan Province.

[2]. Salaman: shake-hand

[3]. So LangkePatamuan: longhouse for meeting. So langkepatamuan is the oldest longhouse of Taman people.

[4]. REFERENCES

[5]. Capon. David Smith. Architectural Theory Volume One. The Vitruvian Fallacy. (Wiley. England. 1999)

[6]. Frampton, Kenneth. Studies in Tectonic Culture. The Poetic of Construction in Nineteenth and Twentieth Century Architecture.(The MIT Press. Cambridge. 1995)

[7]. Mallgrave, Harry Francis. An Introduction to Architectural Theory. 1968 to The Present.(Wiley BlackWell. New York.2011)

[8]. Mangunwijaya, Romo. Wastu Citra. (PT Gramedia. Jakarta. 1985)

[9]. Mitrovic, Branco. Philosophy for Architects.( Princeton Architectural Press. New York. 2011)

[10]. Prijotom, Josef.Nusantara Architecture. To Certainty. (WastuLanasGrafika. Surabaya. 2004).

[11]. Salvador, Mario. The Strength of Architecture. Why Buildings Stand Up.( WW Norton and Company. New York.1980).

[12]. Winzeler, Robert T. The Architecture about Life and Death. (University of Hawai'i Press. Honolulu.1999). 